\title{
COMPARISON OF SILICA AND SODIUM TRISILICATE GLASS SURFACES CREATED BY MOULDING AND BREAKING - - MD SIMULATION
}

\author{
\#JAN MACHÁČEK*, ONDREJ GEDEON*, MAREK LIŠKA** \\ *Department of Glass and Ceramics, University of Chemistry and Technology, Prague (UCT Prague), \\ Technická 5, 16628 Prague, Czech Republic \\ **Fun Glass - Vitrum Laugaricio - Joint Glass Center of IIC SAS, TnU AD, and FChPT STU, \\ Študentská 2, 91150 Trenčin, Slovakia \\ \#E-mail: Jan.Machacek@vscht.cz
}

Submitted October 15, 2021; accepted December 10, 2021

\begin{abstract}
Keywords: Silicate glass, Sodium, Silica, Glass surface, Molecular dynamics, Relaxation
Using a classical molecular dynamics (MD) simulation, bulk $\mathrm{SiO}_{2}$ and $\mathrm{Na}_{2} \mathrm{O} \cdot 3 \mathrm{SiO}_{2}$ glasses were prepared. Then, glassy systems with surfaces were prepared by two different methods. In the first rather traditional method, the surface of the glass was created by dividing the bulk sample by a plane and inserting a sufficiently thick vacuum layer. The system was then relaxed at elevated temperatures (up to $3000 \mathrm{~K}$ ). This situation roughly corresponds to the glass-breaking process. In the second method, the surface was present from the beginning and was maintained by an external force field that mimics the wall of the mould. The moulded surface was again relaxed at elevated temperatures (up to $3000 \mathrm{~K}$ ). This situation roughly corresponds to the glass forming process. The structure of the glass surface was compared with that of basic bulk glass using the radial distribution function of the $\mathrm{Si}-\mathrm{Si}, \mathrm{Si}-\mathrm{O}, \mathrm{O}-\mathrm{O}$ and $\mathrm{Na}-\mathrm{O}$ pairs, the coordination numbers and the number of shared edges of the $\mathrm{SiO}_{4}$ tetrahedra. When the glassy systems with surfaces were compared, the number and density curves of the atoms ( $\mathrm{Si}, \mathrm{O}, \mathrm{Na}$ ) or groupings (bridging and non-bridging $\mathrm{O}, Q^{n}$ units) were used depending on the $Z$ coordinate. It is clear from the comparison that the surface-moulding method generates significantly less surface defects, such as shared edges of $\mathrm{SiO}_{4}$ tetrahedra (in the case of silica glass), while giving a relatively smoother surface. In the case of the $\mathrm{Na}_{2} \mathrm{O} \cdot 3 \mathrm{SiO}_{2}$ glass, a notable increase in the sodium cation numbers was found in the surface layer. This study is the initial part of extensive research activities on the topic of functional modifications of glass surfaces.
\end{abstract}

\section{INTRODUCTION}

Many glass properties are closely related to the surface structure. It is worth mentioning the mechanical strength associated with surface defects. The chemical reactivity of a glass surface is certainly related to the chemical resistance of the glass in a corrosive environment, but also to the deliberate formation of functional layers, the objective of which is to improve or change the surface properties. First, there is a change in the optical properties of the glass, but also an increase in the chemical resistance, or even the ability to catalyse chemical processes. $[14,15]$ These applications require funda-mental research on the glass surface structure and properties; a molecular simulation is one of the powerful tools that can be used in this context.

The glass surface can be created in principle by at least two different procedures. First, the surface is formed at the interface between the glass melt and the gaseous, liquid, or solid phase. It can be undertaken, for example, by blowing, floating, or shaping glass in a mould. Second, the surface is created from a solid state by grinding, polishing, etching, fracturing, etc. It is clear that both processes will lead to more or less different results because the relaxation of the newly created surface takes place under different conditions, at least at different temperatures, which is worth mentioning. For moulded glass, the surface energy will be reduced by the volume diffusion and by chemical reactions at the interface of the liquid phase, while the energy of the fractured glass will be predominantly decreased due to surface chemical reactions and the surface diffusion.

A slightly different situation occurs in the case of classical molecular simulations of the glass surface. Just as with the simulation of molecular dynamics (MD) of bulk glasses, the glass surface simulation serves as a supporting tool for the study of the atomic structure and glass dynamics, which is often difficult to implement experimentally. Unfortunately, unlike the bulk glass, where the atomic structure is essentially homogeneous, the glass surface is problematic in two aspects. The first aspect is the choice of a suitable model of the force interactions between the atoms $[2,5]$. It is simply noted that, for classical MD simulations of oxide glasses, the presence of fixed-charge anions and cations is often assumed, which in itself limits any possible chemical changes on the glass surface. 
The second aspect is related to the surface formation. Most often, the surface is created by the MD simulation by simply bisecting the bulk glass by a vacuum layer [10]. The distribution of atoms on one surface or the other is not determined by energy and bonding reasons, as with brittle fractures, but is given by purely geometric reasons. Therefore, the resulting MD glass surface must be relaxed at high temperatures to enable the new equilibrium surface configuration. The surface formed in this way shows a relatively large number of defects. In silica glass, the sharing of edges between two $\mathrm{SiO}_{4}$ tetrahedra $[3,10]$ dominates among the defects.

The other two methods of surface formation using MD simulation, e.g., mentioned recently in the article [10], are a free surface formation from the melt in a vacuum and a surface formation by fracture under tensile stress. However, these methods provide a rather uneven surface.

The question is, therefore, whether to choose an alternative procedure for creating the glass surface in the hope that the resulting surface quality will be more realistic, i.e., few structural defects, relatively small roughness, etc. In an analogy with the creation of a real glass surface by moulding, this procedure can also be imitated by the MD simulation. The simplest seems to simulate a mould as two solid impenetrable walls between which the MD glass is formed. The aim of this work is to prepare the surface of silica and $\mathrm{Na}_{2} \mathrm{O} \cdot 3 \mathrm{SiO}_{2}$ glass both by the traditional method of 'breaking' and by the method of 'moulding'. The structures of the two glasses are then compared with each other and with the bulk glass structure.

\section{SIMULATION}

\section{MD glass system specification}

The model of the atomic structure of silica $\left(\mathrm{SiO}_{2}\right)$ and sodium trisilicate $\left(\mathrm{Na}_{2} \mathrm{O} \cdot 3 \mathrm{SiO}_{2}\right)$ glass was prepared using the method of classical molecular dynamics. MD simulations were performed using DLPOLY 4 software [1]. The cubic computing cell contained 2400 silicon atoms and 4800 oxygen atoms. The length of the edge of the computing cell was $44.874 \AA$, corresponding to a density of $2.65 \mathrm{~g} \cdot \mathrm{cm}^{-1}$. This value corresponds to the $\mathrm{MD} \mathrm{SiO}_{2}$ glass at a standard temperature and pressure using the Beest Kramer van Santen (BKS) pair potential [2]. The density is higher than the experimental density of the silica glass, that is, $2.2 \mathrm{~g} \cdot \mathrm{cm}^{-1}$. The choice of the system density is based on the results published in the article [5].

\section{Interatomic forces}

Interatomic forces among the silicon and oxygen atoms have been described with the BKS potential. This potential implies an electrostatic interaction among the ions with an effective charge of 2.4 for silicon and -1.2 for oxygen, and the Buckingham potential for shortrange pair interactions, i.e., an exponential repulsion term, and an attractive dispersion term. The main advantage of this potential is both the wide spread among people simulating silica materials by $\operatorname{MD}[7,5,6]$ and quite a good description of the glass structure despite of its paired character. Its disadvantage is that it does not reproduce the correct stable modification of quartz at normal temperatures [7], predicts a higher melting point of silicates [11], generally gives a larger average $\mathrm{Si}-\mathrm{O}-\mathrm{Si}$ angle, and also shows a wider distribution. A known disadvantage, although a rather technical one, of the BKS potential is that it diverges to negative values at short distances of atoms. This is solved by replacing this critical part of the interaction potential with another appropriate smooth function. However, the dispersion term makes an unrealistically large contribution to the interaction of the atoms [7]. Consequently, the short-range potential decreases more slowly with the distance of the atoms. Hence, the cut-off limit of the short-range part of the potential must be set far enough; in our simulations, $10 \AA$. The potential was shifted to zero at this distance to overcome the discontinuity of the potential energy.

\section{Cooling procedure}

The bulk MD glass was prepared by the simulated cooling of a system of ions randomly distributed in the computing cell. The integration time step of the equations of motion was set to $1 \mathrm{fs}$. The initial temperature was $5000 \mathrm{~K}$ and the final one was $100 \mathrm{~K}$. Cooling was performed according to curve 1 presented in Figure 1. The equilibration at each temperature included the Evans thermostat for $2.5 \mathrm{ps}$ and adiabatic relaxation steps for $7.5 \mathrm{ps}$. At a temperature of $5000 \mathrm{~K}$, the equilibration was extended to $25 \mathrm{ps}$. The temperature was gradually reduced in steps of $100 \mathrm{~K}$. Three independent simulations

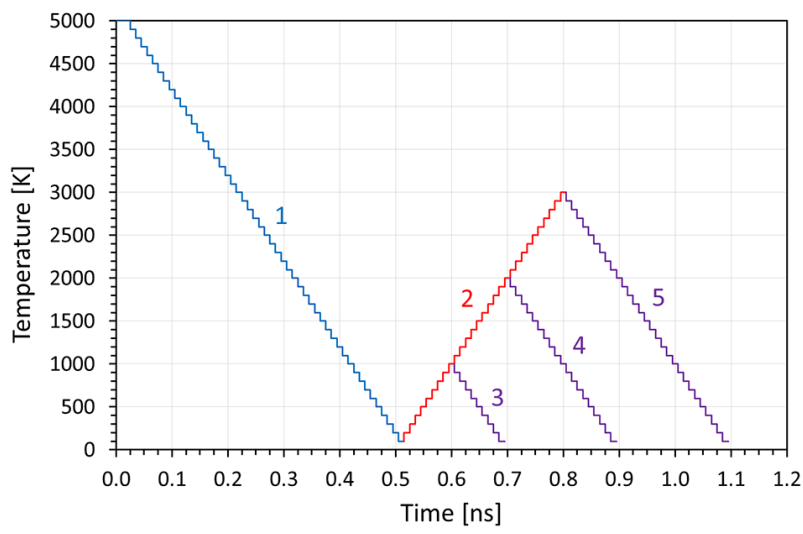

Figure 1. Cooling/heating curves of the MD simulations: 1 - preparation of the bulk (and the moulded) MD glass by cooling from a random configuration of atoms; 2 - reheating of the MD glass with broken or moulded surfaces; 3 - cooling from $1000 \mathrm{~K} ; 4$ - cooling from $2000 \mathrm{~K} ; 5$ - cooling from $3000 \mathrm{~K}$. 
were performed, from which the corresponding mean values of the properties and their standard deviations were calculated.

\section{Making the glass surface with MD}

In this work, two MD surface preparation methods were used. The first method should mimic the creation of a surface by breaking (hereafter 'broken glass'), while the other should mimic 'moulding' (hereafter 'moulded glass'). The first method is much more common in MD surface simulations.

\section{Broken glass surface}

The surface is formed by inserting a vacuum layer into the cubic computing cell in the $\mathrm{Z}$ direction. The thickness of this layer should ensure that there is no interaction between the atoms of both surfaces. From a technical point of view (concerns the DLPOLY program), it is only a multiplication of the grid vector in the $\mathrm{Z}$ direction by a suitable constant. The atomic coordinates do not need to be adjusted because they are in absolute units and the origin of the coordinate system is in the centre of the computing cell. Therefore, the three-dimensional periodic boundary conditions were retained. In this work, the new grid vector was twice the original.

The surface was subjected to relaxation at elevated temperatures. Three independent systems were heated according to curve 2 in Figure 1 at temperatures of $1000 \mathrm{~K}, 2000 \mathrm{~K}$ and $3000 \mathrm{~K}$. After reaching the peak temperatures, the systems were cooled down along curves 3, 4 and 5 to $100 \mathrm{~K}$. Three independent systems were obtained for each relaxation temperature.

\section{Moulded glass surface}

The atoms were initially randomly placed in a computing cell $44.874 \times 44.874 \times 89.748 \AA^{3}$ with the $Z$ coordinates ranging from -44.874 to $44.874 \AA$. Atoms exceeding were subject to an external force that simulates the elastic reflection of a solid wall perpendicular to the direction of the $z$-axis:

$$
\begin{array}{ll}
F_{\text {wall }}=\operatorname{sign}(z) \cdot A\left(z_{0}-|z|\right) & |z| \geq z_{0} \\
F_{\text {wall }}=0 & |z|<z_{0}
\end{array}
$$

where $A=10 \mathrm{eV} / \AA^{2}$ represents the wall stiffness. The value $A$ was set by trial and error to achieve the optimal wall stiffness, which ensures the stability of the MD simulation. A low value of $A$ would cause the atoms to penetrate the wall; however, a high value of $A$ would cause poor energy conservation. The external force mainly contributes to the total energy at higher temperatures, whereas its contribution to the total energy is negligible at room temperature. However, the resulting glass structure is significantly affected by this external potential, as will be shown below. The MD glass was subsequently cooled at the same rate as the bulk glass, that is, according to curve 1 in Figure 1. Just as in the case of the broken glass, the surface was relaxed. The external potential was turned off and the 'moulded glasses' were gradually heated to $1000 \mathrm{~K}, 2000 \mathrm{~K}$ and $3000 \mathrm{~K}$ along curve 2 in Figure 1 and then cooled down along curves 3,4 , and 5 .

\section{Analysis of MD glass}

The surface energy of the MD glass, $\gamma$, was calculated at a temperature of $100 \mathrm{~K}$ according to the relation:

$$
\gamma=\frac{E_{\text {slab }}-E_{\text {bulk }}}{2 L^{2}}
$$

where $E_{\text {slab }}$ is the total energy of the computing cell containing the glass slab, $E_{\text {bulk }}$ is the total energy of the computing cell of the bulk glass, and $L^{2}$ is the surface area [13].

The structure of the glass was characterised by partial-pair radial distribution functions (RDFs), an average coordination number as a function of the radius $(\mathrm{CRN})$, and the number of atoms in the first coordination sphere (CRD). The cut-off radius of the first coordination sphere corresponds to the local RDF minimum following the first RDF peak for the given type of atoms. The connectivity of the silicate network was also characterised by the distribution of $\mathrm{Q}^{n}$ units, where $n$ is the number of bridging oxygens of the quaternary silicon.

The structure of the MD glass with the surface was described by the z-density, i.e., the one-dimensional density of atoms (or number of atoms) of a given species along the z-axis.

Estimation of surface roughness was performed using a spherical probe of $1 \AA$ radius that was placed on the nodes of the square grid consisting of $127 \times 127$ points, that is, with a pitch of $0.36 \AA$. The radius of the surface atoms was set to the radius which corresponded to the tabulated value for the oxygen anion, that is, $1.26 \AA$. Quantification was performed using the mean arithmetic surface roughness, $S_{\mathrm{a}}$ :

$$
S_{\mathrm{a}}=\frac{1}{n} \sum_{i=1}^{n}\left|z_{\mathrm{i}}-\bar{z}\right|
$$

where $z_{i}$ is the coordinate of the probe tip in touch with the surface at point $i, n$ is the number of points, and $\bar{z}$ is the average $z$-coordinate and the index $i$ passes through $n$ points of the grid.

\section{RESULTS}

\section{Surface energy}

The surface energy of the broken and moulded glass can be seen in Figure 2 and Figure 3 for the $\mathrm{SiO}_{2}$ glass and $\mathrm{Na}_{2} \mathrm{O} \cdot 3 \mathrm{SiO}_{2}$ glass, respectively. The surface energy of the unrelaxed broken glass significantly 
exceeds the surface energy of the relaxed glasses, but also the unrelaxed moulded $\mathrm{Na}_{2} \mathrm{O} \cdot 3 \mathrm{SiO}_{2}$ glass. The surface energy of the latter one is identical (within the standard deviation) to the surface energy of the moulded

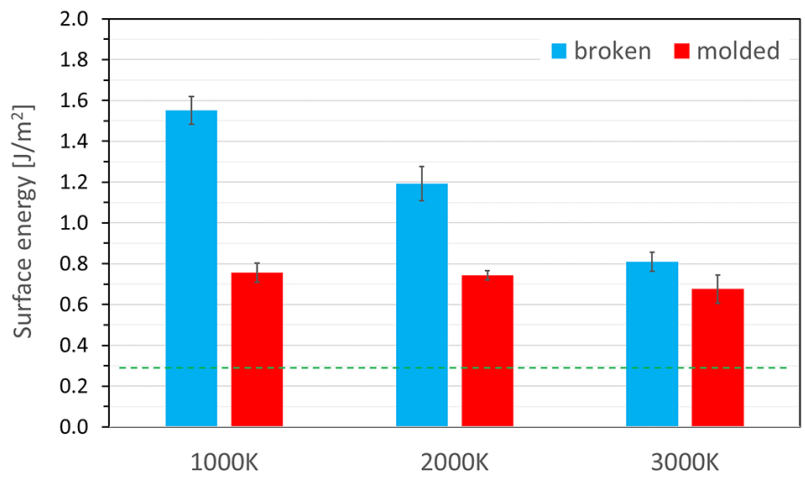

Figure 2. The surface energy of the broken and moulded $\mathrm{SiO}_{2}$ MD glass relaxed at $1000 \mathrm{~K}, 2000 \mathrm{~K}$ a $3000 \mathrm{~K}$. The dashed line indicates the experimental surface energy of the $\mathrm{SiO}_{2}$ glass at about its glass transition temperature. The error bars are the standard deviations.

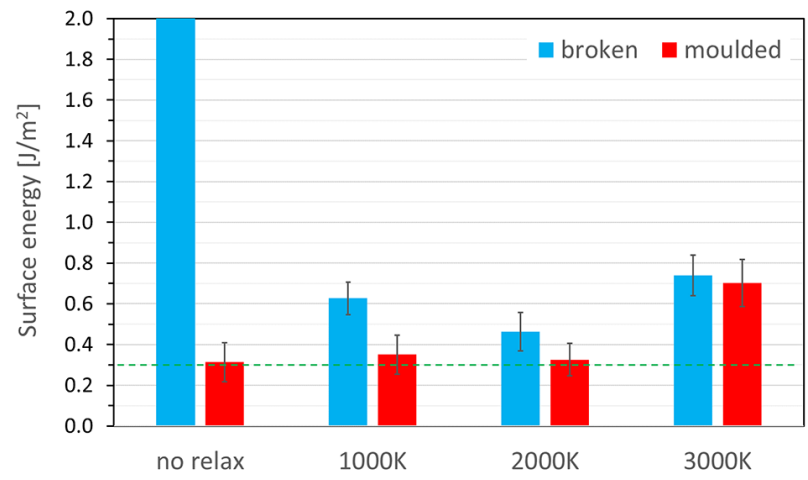

Figure 3. Surface energy of the broken and moulded $\mathrm{Na}_{2} \mathrm{O} \cdot 3 \mathrm{SiO}_{2}$ MD glass unrelaxed and relaxed at 1000, 2000 and $3000 \mathrm{~K}$. The surface energy of the broken $\mathrm{Na}_{2} \mathrm{O} \cdot 3 \mathrm{SiO}_{2}$ MD glass (the truncated first bar) reaches up to $5.2 \mathrm{~J} \cdot \mathrm{m}^{2}$. The dashed line indicates the experimental surface energy of the $\mathrm{Na}_{2} \mathrm{O} \cdot 3 \mathrm{SiO}_{2}$ glass at approximately its glass transition temperature. The error bars are the standard deviations.

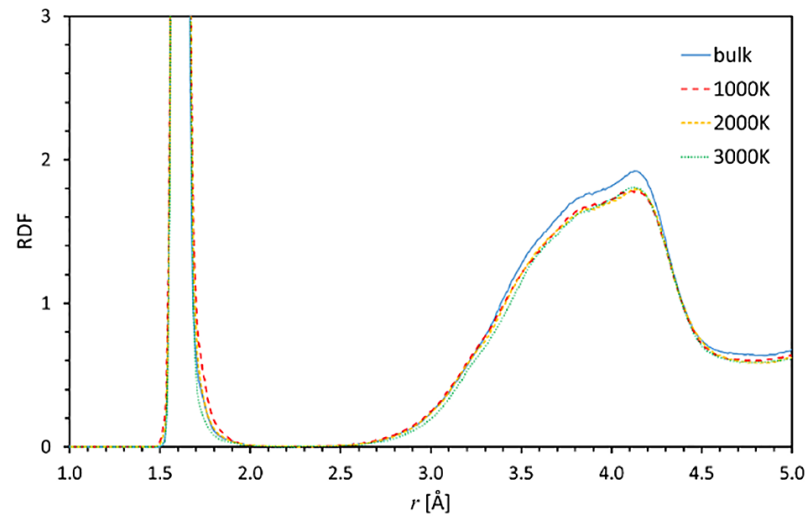

a) broken $\mathrm{SiO}_{2}-\mathrm{Si}-\mathrm{O}$ pair glass relaxed at $1000 \mathrm{~K}$ and $2000 \mathrm{~K}$. The surface energy of the broken glasses is always higher than that for the moulded glasses, except for the relaxation temperature of $3000 \mathrm{~K}$, when the temperature is high enough to allow the complete reconstruction of the surface from a liquid state. It was not observed for the $\mathrm{SiO}_{2}$ glass as the glass is deeply below $T_{g}$.

\section{RDF and CRN}

Figure 4 shows the RDFs of the $\mathrm{Si}-\mathrm{O}, \mathrm{O}-\mathrm{O}$, and $\mathrm{Si}-\mathrm{Si}$ pairs for the simulated $\mathrm{SiO}_{2}$ glass. As can be seen, the bulk glass differs from the glass slabs. The formation of new peaks on the RDF $\mathrm{O}-\mathrm{O}$ and the RDF $\mathrm{Si}-\mathrm{Si}$ of the broken glass at $2.2 \AA$ and $2.5 \AA$, respectively, corresponding to the generation of a shared edge between two $\mathrm{SiO}_{4}$ tetrahedra, can be observed. CRN ( $\mathrm{Si}-\mathrm{O})$ (Table 1) slightly exceeds four atoms due to the presence of five-coordinated silicon atoms. A small number of such defects is typical for MD simulations of $\mathrm{SiO}_{2}$ glass using the BKS potential [5]. $\mathrm{CRN}(\mathrm{O}-\mathrm{O})$ and

Table 1. Average coordination numbers for the $\mathrm{SiO}_{2}$ bulk glass, the broken glass, and the moulded glass relaxed at $3000 \mathrm{~K}$. Average values of three independent simulations, including the standard deviations.

\begin{tabular}{lcccc}
\hline & $\begin{array}{c}\text { Cut-off } \\
{[\AA]}\end{array}$ & $\begin{array}{c}\text { Bulk } \\
\text { glass }\end{array}$ & $\begin{array}{c}\text { Broken } \\
\text { glass }\end{array}$ & $\begin{array}{c}\text { Moulded } \\
\text { glass }\end{array}$ \\
\hline $\mathrm{Si}-\mathrm{O}$ & 2.2 & $4.03 \pm 0.01$ & $4.02 \pm 0.01$ & $4.02 \pm 0.01$ \\
$\mathrm{O}-\mathrm{O}$ & 3 & $6.67 \pm 0.02$ & $6.50 \pm 0.04$ & $6.49 \pm 0.03$ \\
$\mathrm{Si}-\mathrm{Si}$ & 3.4 & $4.12 \pm 0.01$ & $4.07 \pm 0.03$ & $4.07 \pm 0.02$ \\
\hline
\end{tabular}

Table 2. Average number of shared edges.

\begin{tabular}{lcccc}
\hline & $\begin{array}{c}\text { Bulk } \\
\text { glass }\end{array}$ & $\begin{array}{c}\text { Unrelaxed } \\
\text { moulded glass }\end{array}$ & $\begin{array}{c}\text { Broken } \\
\text { glass }\end{array}$ & $\begin{array}{c}\text { Moulded } \\
\text { glass }\end{array}$ \\
\hline $1000 \mathrm{~K}$ & $3 \pm 1$ & $7 \pm 3$ & $36 \pm 4$ & $6 \pm 3$ \\
$2000 \mathrm{~K}$ & & & $24 \pm 5$ & $7 \pm 3$ \\
$3000 \mathrm{~K}$ & & & $20 \pm 2$ & $11 \pm 3$ \\
\hline
\end{tabular}

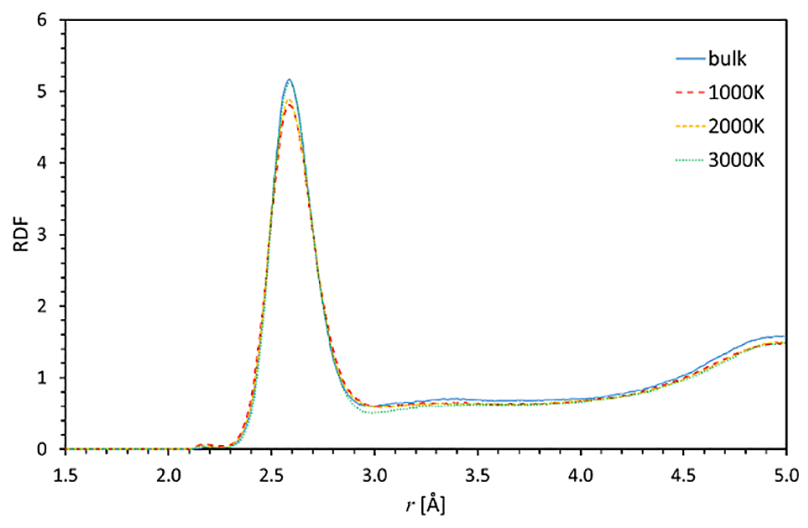

b) broken $\mathrm{SiO}_{2}-\mathrm{O}-\mathrm{O}$ pair

Figure 4. Comparison of the partial radial distribution functions of the broken and moulded glass relaxed at $1000 \mathrm{~K}, 2000 \mathrm{~K}$, and $3000 \mathrm{~K}$. The bulk $\mathrm{SiO}_{2} \mathrm{MD}$ glass is included as a reference. (Continue on next page) 


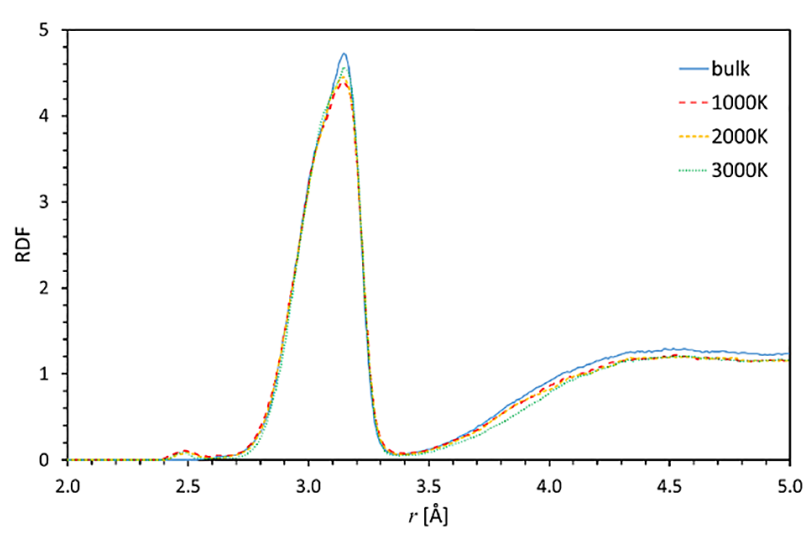

c) broken $\mathrm{SiO}_{2}-\mathrm{Si}-\mathrm{Si}$ pair

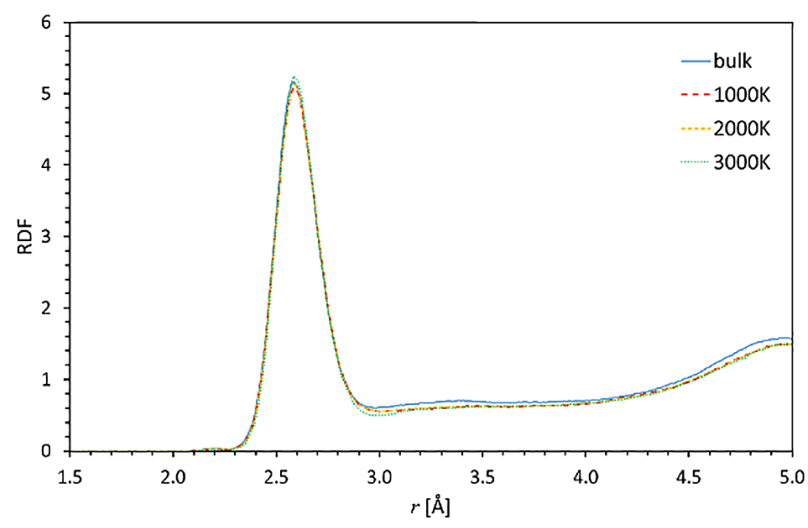

e) moulded $\mathrm{SiO}_{2}-\mathrm{O}-\mathrm{O}$ pair

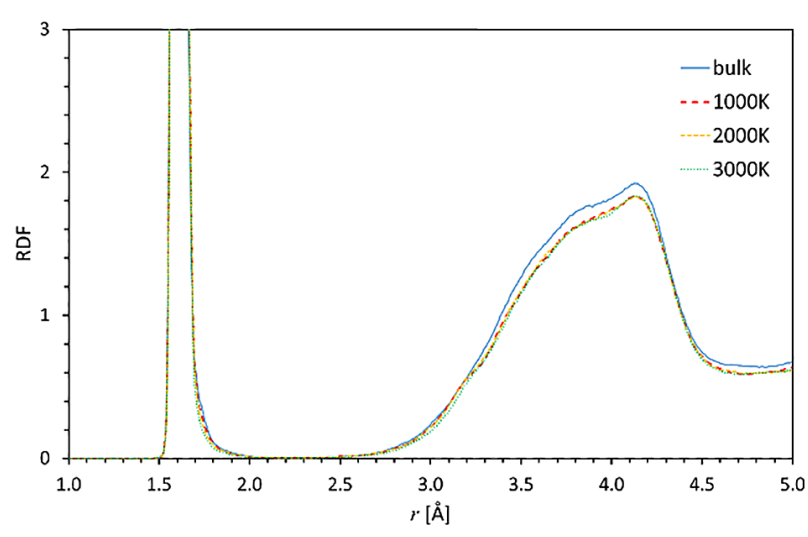

d) moulded $\mathrm{SiO}_{2}-\mathrm{Si}-\mathrm{O}$ pair

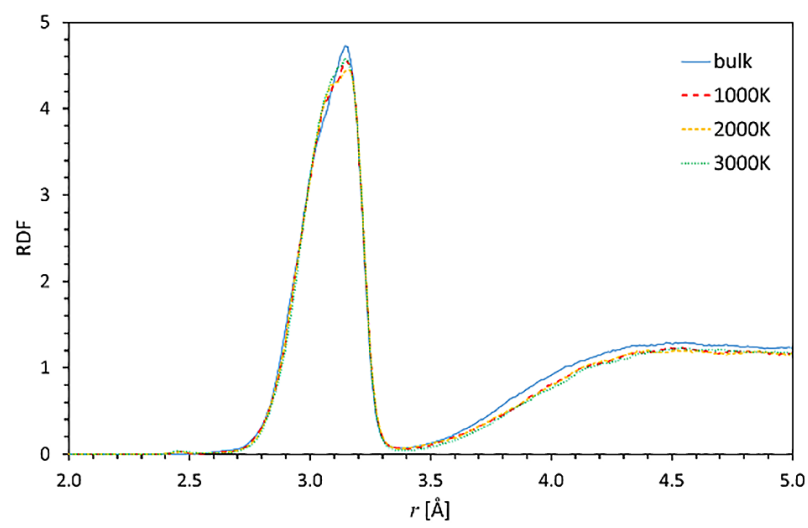

f) moulded $\mathrm{SiO}_{2}-\mathrm{Si}-\mathrm{Si}$ pair

Figure 4. Comparison of the partial radial distribution functions of the broken and moulded glass relaxed at $1000 \mathrm{~K}$, $2000 \mathrm{~K}$, and $3000 \mathrm{~K}$. The bulk $\mathrm{SiO}_{2} \mathrm{MD}$ glass is included as a reference.

$\mathrm{CRN}(\mathrm{Si}-\mathrm{Si})$ are significantly lower for the glass slabs. This can be attributed to the presence of the surfaces. Figure 5 shows the RDFs of the $\mathrm{Na}-\mathrm{O}, \mathrm{O}-\mathrm{O}$ and $\mathrm{Na}-\mathrm{Na}$ pairs for the simulated $\mathrm{Na}_{2} \mathrm{O} \cdot 3 \mathrm{SiO}_{2}$ glass. Again, the bulk glass differs from the glass slabs. The other RDFs of the simulated $\mathrm{Na}_{2} \mathrm{O} \cdot 3 \mathrm{SiO}_{2}$ glass, i.e., $\mathrm{Si}-\mathrm{O}, \mathrm{O}-\mathrm{O}$, and $\mathrm{Si}-\mathrm{Si}$, are similar to those of the $\mathrm{SiO}_{2}$ glass.

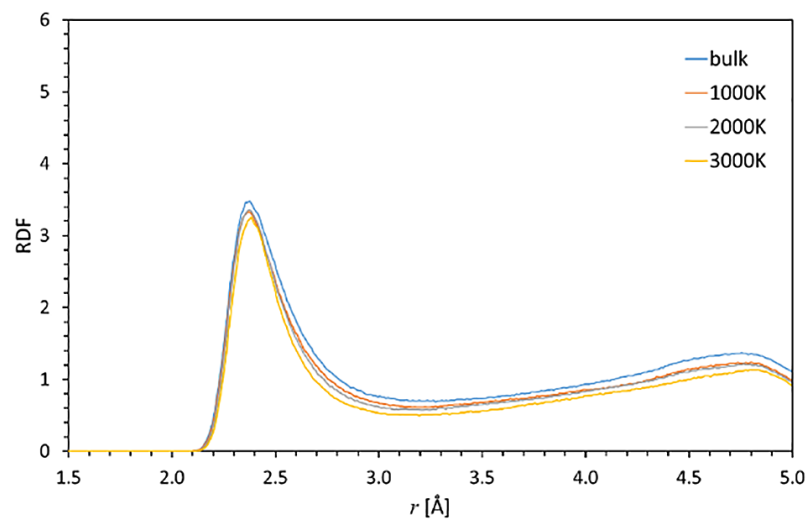

a) broken $\mathrm{Na}_{2} \mathrm{O} \cdot 3 \mathrm{SiO}_{2}-\mathrm{Na}-\mathrm{O}$ pair
Density of atoms along the Z-axis

Figures 6 and 7 show the number of silicon, oxygen, and sodium atoms along the $\mathrm{z}$-axis for the simulated glasses. Figure 6a shows concentration fluctuations in the unrelaxed broken $\mathrm{SiO}_{2}$ glass (the same as for the bulk glass). The unrelaxed moulded glass (Figure 6d) as well as the broken and moulded glasses relaxed at

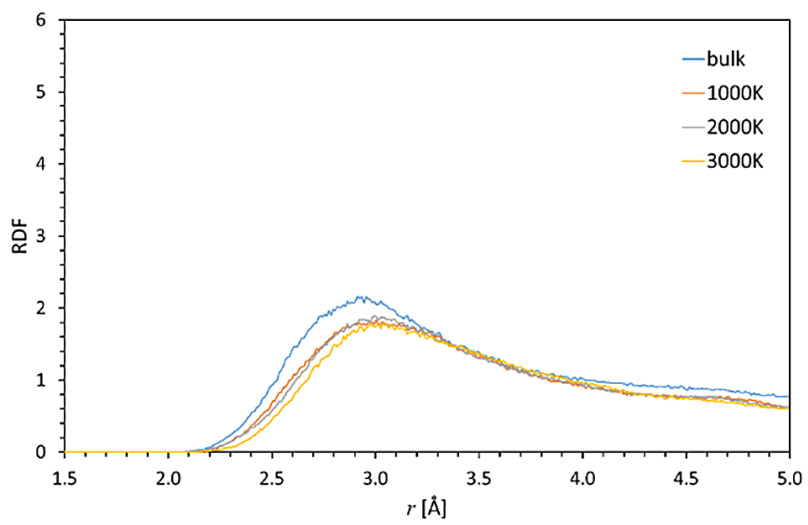

b) broken $\mathrm{Na}_{2} \mathrm{O} \cdot 3 \mathrm{SiO}_{2}-\mathrm{Na}-\mathrm{Na}$ pair

Figure 5. Comparison of the radial distribution functions of the broken and moulded $\mathrm{Na}_{2} \mathrm{O} \cdot 3 \mathrm{SiO}_{2}$ glass relaxed at $1000 \mathrm{~K}, 2000 \mathrm{~K}$, and $3000 \mathrm{~K}$. The bulk $\mathrm{Na}_{2} \mathrm{O} \cdot 3 \mathrm{SiO}_{2}$ glass is included as a reference. (Continue on next page) 


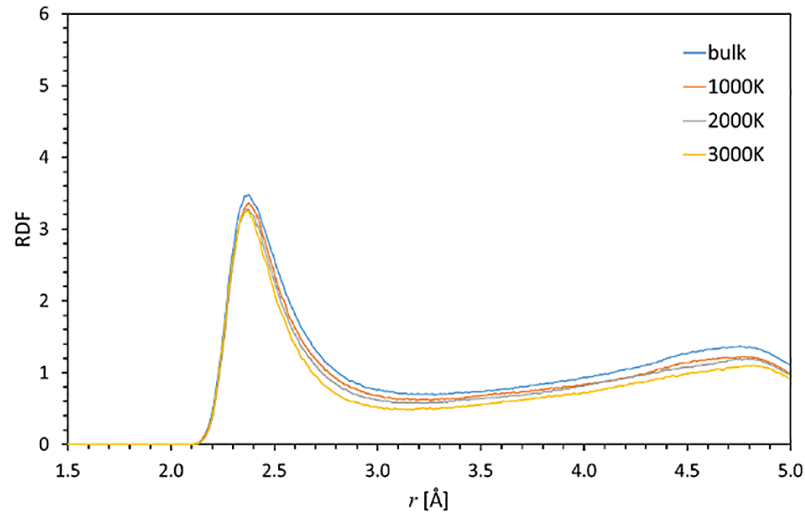

c) moulded $\mathrm{Na}_{2} \mathrm{O} \cdot 3 \mathrm{SiO}_{2}-\mathrm{Na}-\mathrm{O}$ pair

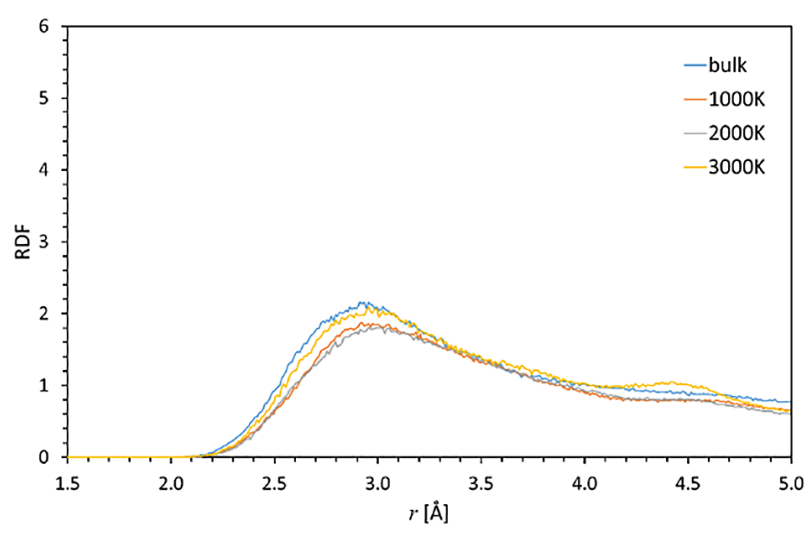

d) moulded $\mathrm{Na}_{2} \mathrm{O} \cdot 3 \mathrm{SiO}_{2}-\mathrm{Na}-\mathrm{Na}$ pair

Figure 5. Comparison of the radial distribution functions of the broken and moulded $\mathrm{Na}_{2} \mathrm{O} \cdot 3 \mathrm{SiO}_{2}$ glass relaxed at $1000 \mathrm{~K}, 2000 \mathrm{~K}$, and $3000 \mathrm{~K}$. The bulk $\mathrm{Na}_{2} \mathrm{O} \cdot 3 \mathrm{SiO}_{2}$ glass is included as a reference.

$1000 \mathrm{~K}$ (Figure 6b,e) show significantly higher numbers of silicon atoms in the surface layer. This can be attributed to the reorientation of silicon tetrahedra to face the interior of the glass to minimise the number of dangling bonds (Figure 8). On the other hand, in the case

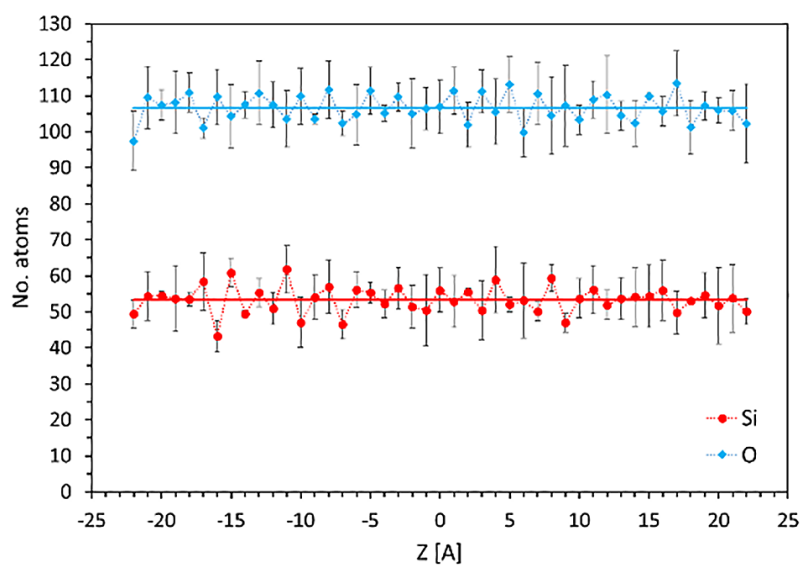

a) broken $\mathrm{SiO}_{2}$ - unrelaxed

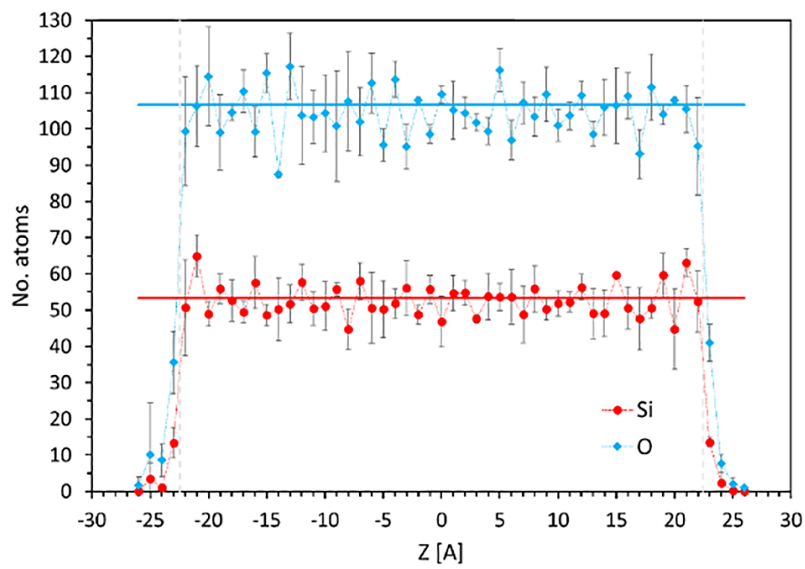

c) broken $\mathrm{SiO}_{2}-3000 \mathrm{~K}$ of the $\mathrm{Na}_{2} \mathrm{O} .3 \mathrm{SiO}_{2}$ glass, no such phenomenon is visible (Figure 9). In Figure 7, it can be clearly seen that the surface layer is enriched in sodium atoms. The glasses relaxed at $3000 \mathrm{~K}$ show a broad surface layer.

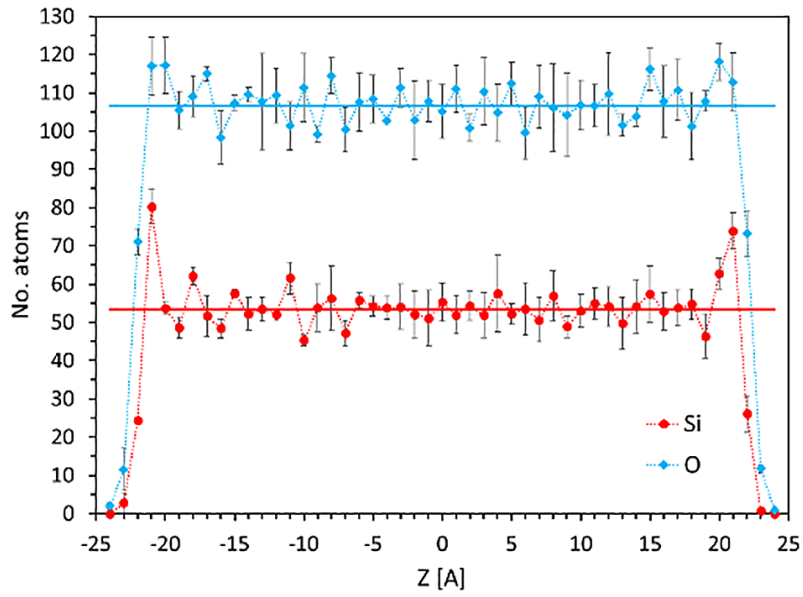

b) broken $\mathrm{SiO}_{2}-1000 \mathrm{~K}$

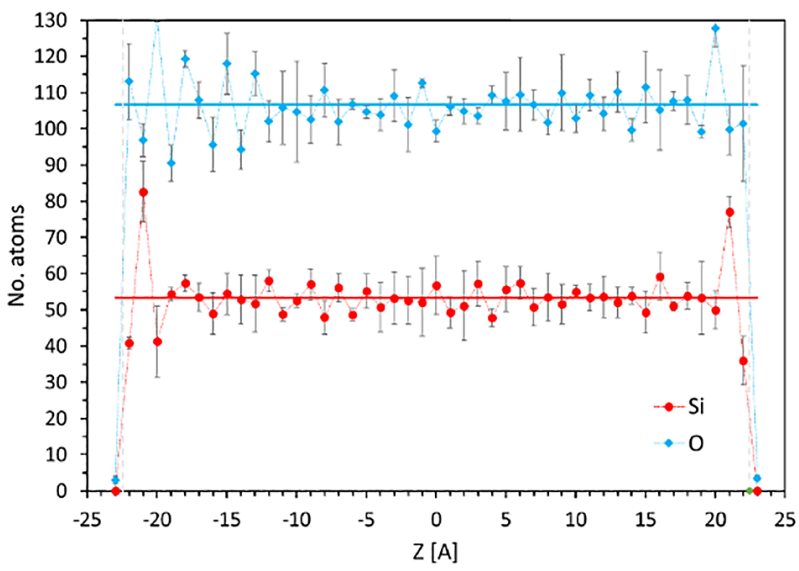

d) moulded $\mathrm{SiO}_{2}$ - unrelaxed

Figure 6. Number of atoms along the $z$-axis in the broken and moulded $\mathrm{SiO}_{2}$ glass. The unrelaxed and relaxed systems at $1000 \mathrm{~K}$ and $3000 \mathrm{~K}$ are shown. The thick solid lines are the average values for the bulk glass. The error bars are the standard deviations. The thin dotted lines serve as a guide for the eyes. (Continue on next page) 


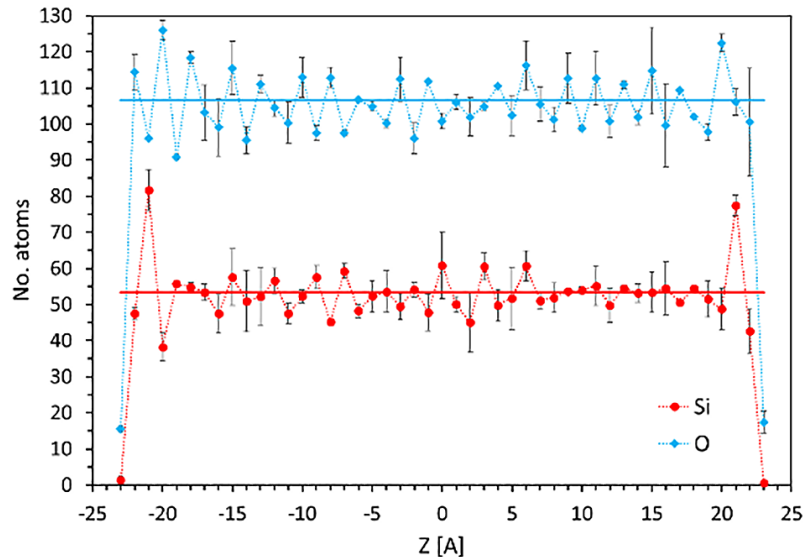

e) moulded $\mathrm{SiO}_{2}-1000 \mathrm{~K}$

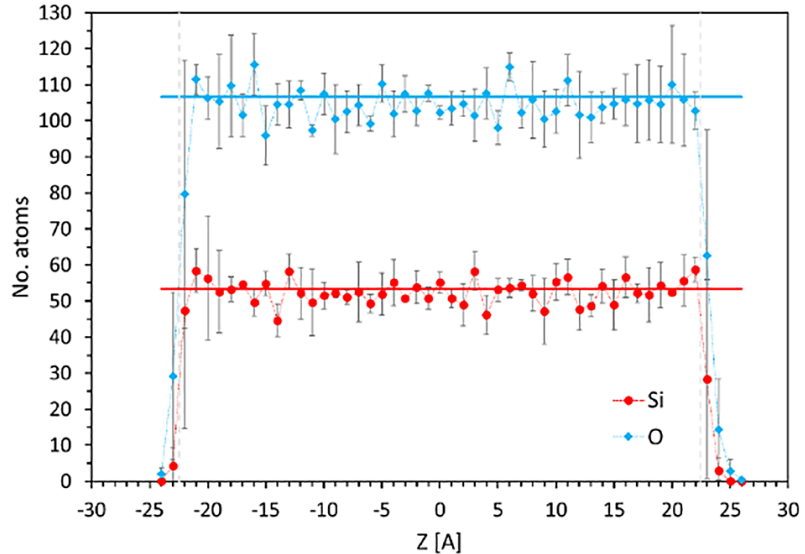

f) moulded $\mathrm{SiO}_{2}-3000 \mathrm{~K}$

Figure 6. Number of atoms along the $z$-axis in the broken and moulded $\mathrm{SiO}_{2}$ glass. The unrelaxed and relaxed systems at $1000 \mathrm{~K}$ and $3000 \mathrm{~K}$ are shown. The thick solid lines are the average values for the bulk glass. The error bars are the standard deviations. The thin dotted lines serve as a guide for the eyes.

Figure 10 shows the oxygen coordination number along the $z$-axis in the broken and moulded $\mathrm{Na}_{2} \mathrm{O} \cdot 3 \mathrm{SiO}_{2}$ glass relaxed at $1000 \mathrm{~K}$. It can be seen that the surface layers are significantly enriched in non-bridging oxygen

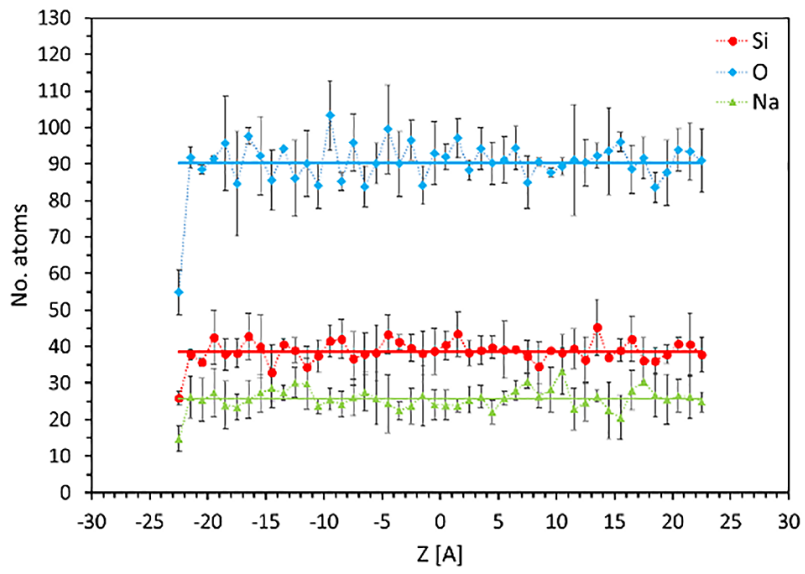

a) broken $\mathrm{Na}_{2} \mathrm{O} \cdot 3 \mathrm{SiO}_{2}$ - unrelaxed

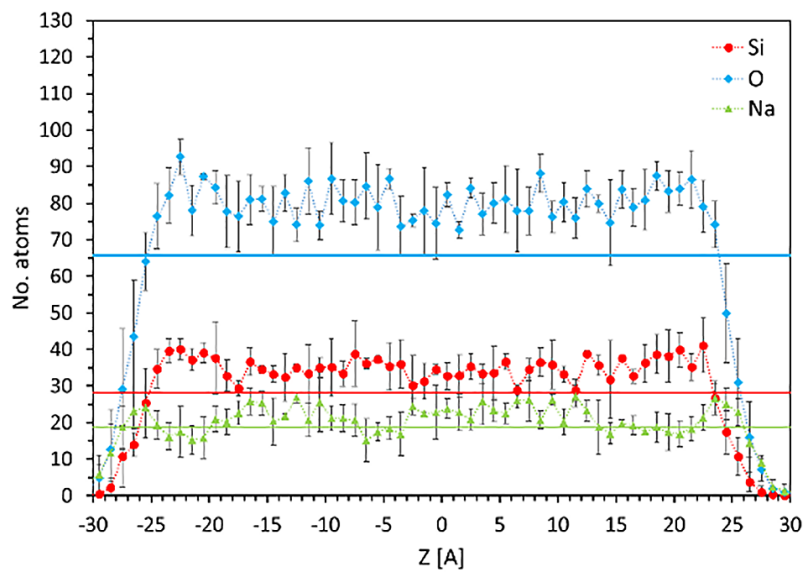

c) broken $\mathrm{Na}_{2} \mathrm{O} \cdot 3 \mathrm{SiO}_{2}-3000 \mathrm{~K}$ atoms, and the adjacent sublayer below is enriched in with bridging oxygen atoms. The enrichment of the surface layer from the non-bridging oxygen affects the distribution of the $\mathrm{Q}^{n}$ units. Figure 11 shows $\mathrm{Q}^{n}$ fractions along

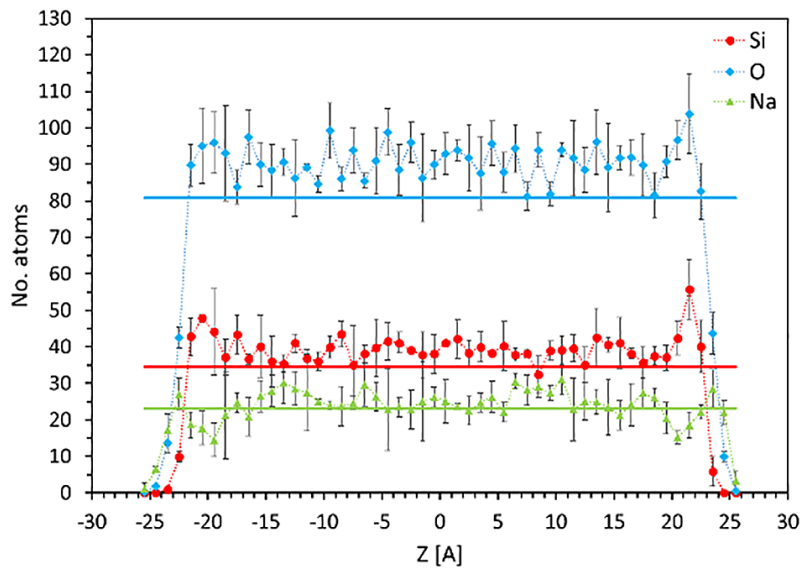

b) broken $\mathrm{Na}_{2} \mathrm{O} \cdot 3 \mathrm{SiO}_{2}-1000 \mathrm{~K}$

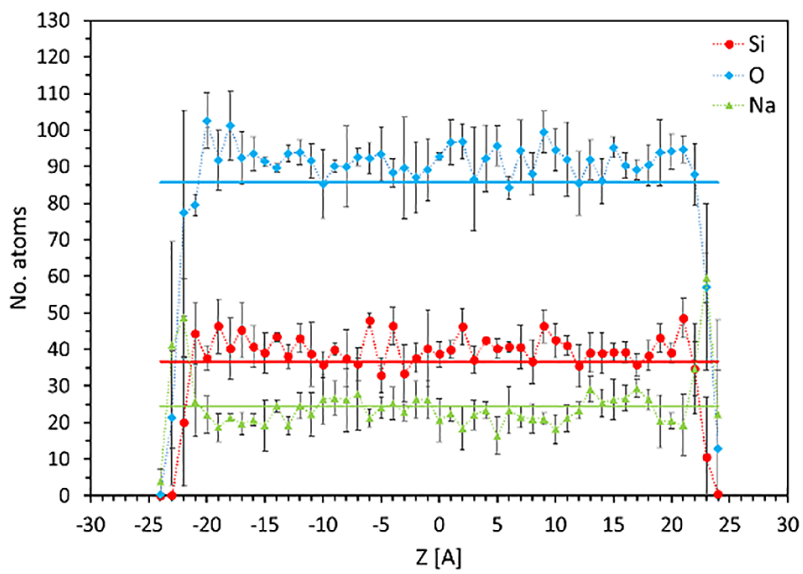

d) moulded $\mathrm{Na}_{2} \mathrm{O} \cdot 3 \mathrm{SiO}_{2}$ - unrelaxed

Figure 7. Number of atoms along the $z$-axis in the broken and moulded $\mathrm{Na}_{2} \mathrm{O} \cdot 3 \mathrm{SiO}_{2}$ glass. Only the relaxed and unrelaxed systems at $1000 \mathrm{~K}$ and $3000 \mathrm{~K}$ are shown. The error bars are the standard deviations. The thin dotted lines serve as a guide for the eyes. (Continue on next page) 


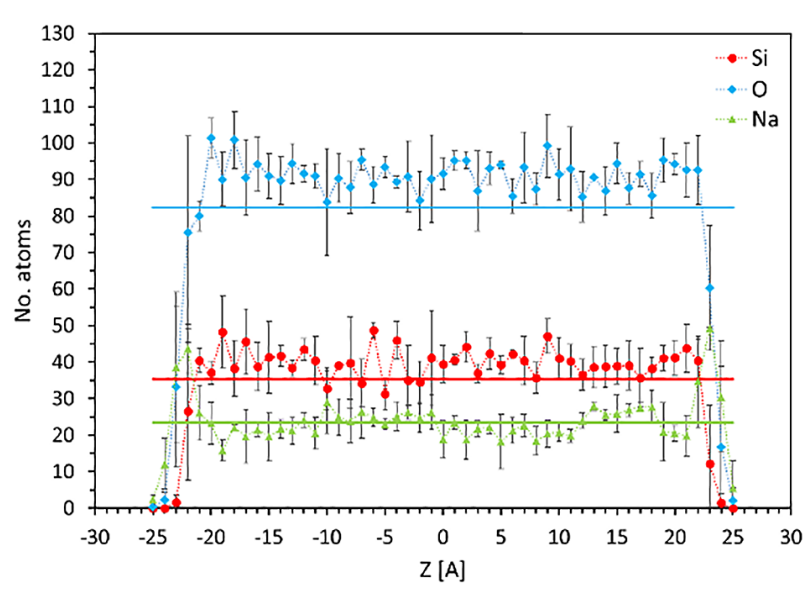

e) moulded $\mathrm{SiO}_{2}-1000 \mathrm{~K}$

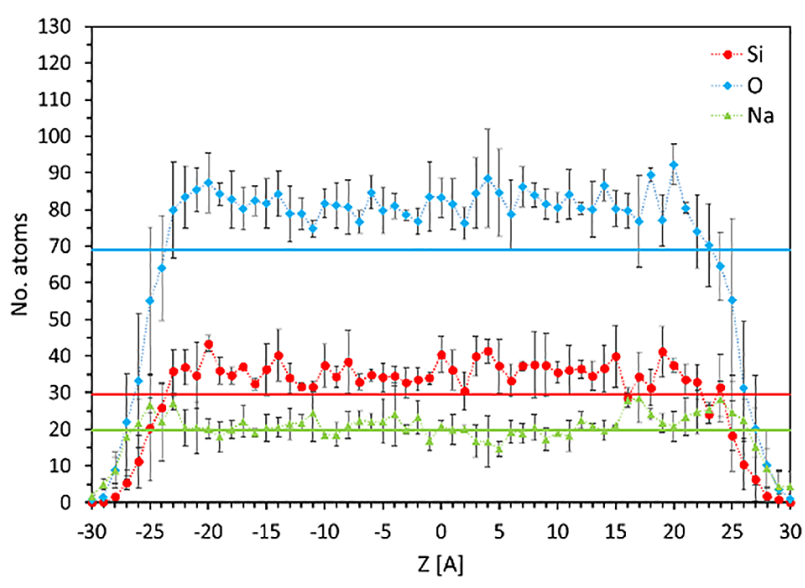

f) moulded $\mathrm{SiO}_{2}-3000 \mathrm{~K}$

Figure 7. Number of atoms along the z-axis in the broken and moulded $\mathrm{Na}_{2} \mathrm{O} \cdot 3 \mathrm{SiO}_{2}$ glass. Only the relaxed and unrelaxed systems at $1000 \mathrm{~K}$ and $3000 \mathrm{~K}$ are shown. The error bars are the standard deviations. The thin dotted lines serve as a guide for the eyes.

the $z$-axis in the broken and the moulded $\mathrm{Na}_{2} \mathrm{O} \cdot 3 \mathrm{SiO}_{2}$ glass relaxed at $1000 \mathrm{~K}$. Although the abundance of the $\mathrm{Q}^{n}$ units is lower, the increased proportion of $\mathrm{Q}^{2}$ and $\mathrm{Q}^{1}$ on the surface is obvious. At the same time, the number of $\mathrm{Q}^{4}$ units located below the surface of the glass increased. This effect is even more pronounced in the moulded $\mathrm{Na}_{2} \mathrm{O} \cdot 3 \mathrm{SiO}_{2}$ glass.

\section{Roughness}

Figures 12 and 13 show the surface roughness of the $\mathrm{SiO}_{2}$ and $\mathrm{Na}_{2} \mathrm{O} \cdot 3 \mathrm{SiO}_{2}$ glass as a function of the relaxation temperature. For comparison, the roughness of the unrelaxed broken and moulded glasses is also given. In the case of the $\mathrm{SiO}_{2}$ glass, at a relaxation temperature of $1000 \mathrm{~K}$, the roughness of the glass prepared by

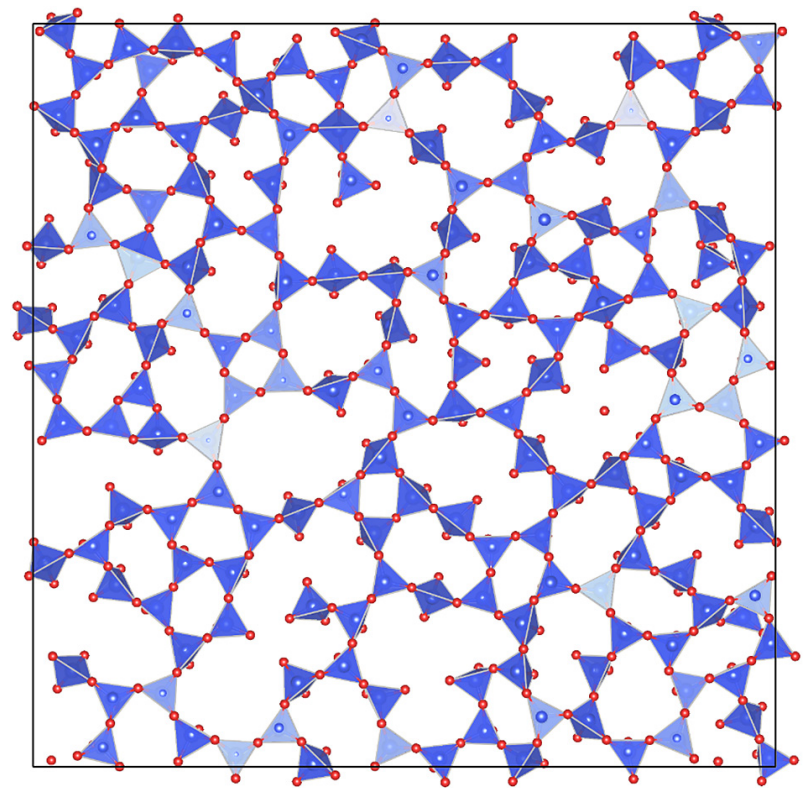

Figure 8. Surface of the unrelaxed moulded $\mathrm{SiO}_{2}$ glass. The length of the cell edge is $44.87 \AA$. The layer thickness is $3 \AA$. Most of the tetrahedra point to the interior of the glass. breaking and moulding is similar and corresponds to the unrelaxed moulded glass. At higher relaxation temperatures, the roughness increases and is higher for the broken glass. Similar trends can be seen for the $\mathrm{Na}_{2} \mathrm{O} \cdot 3 \mathrm{SiO}_{2}$ glass (Figure 13). At $1000 \mathrm{~K}$, the roughness (excluding the broken glass) is similar to that of $\mathrm{SiO}_{2}$ glass. However, at higher relaxation temperatures, the increase in the roughness is accelerated.

\section{DISCUSSION}

The purpose of this paper is to compare two approaches to glass surface formation using an MD simulation. The process of breaking glass creates a surface that has a high energy and must be allowed to relax to saturate the broken bonds. In the case of the pure MD

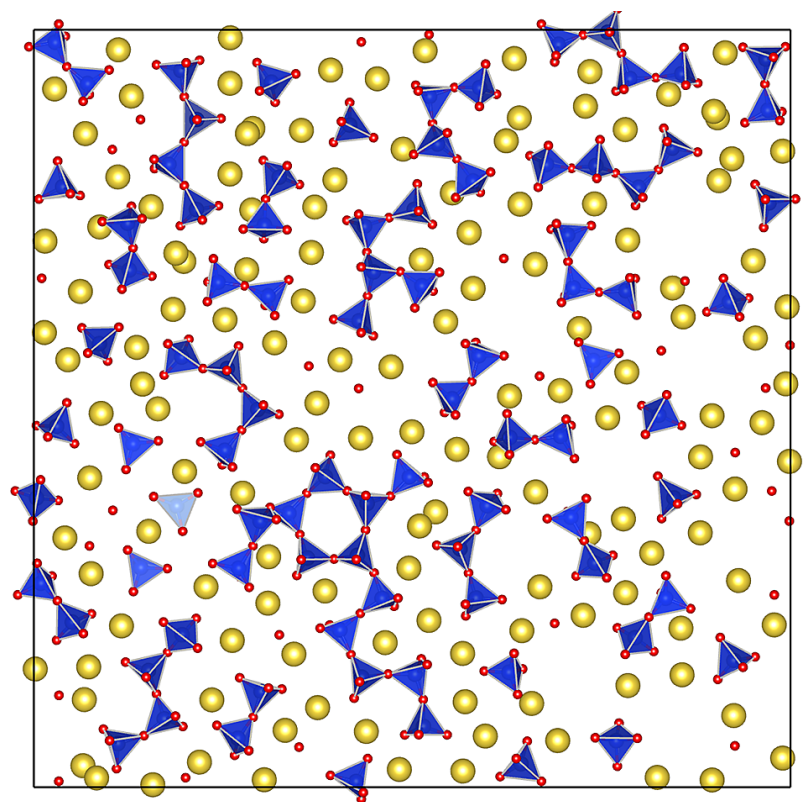

Figure 9. Surface of the unrelaxed moulded $\mathrm{Na}_{2} \mathrm{O} \cdot 3 \mathrm{SiO}_{2}$ glass. The length of the cell edge is $46.16 \AA$. The layer thickness is $3 \AA$. 


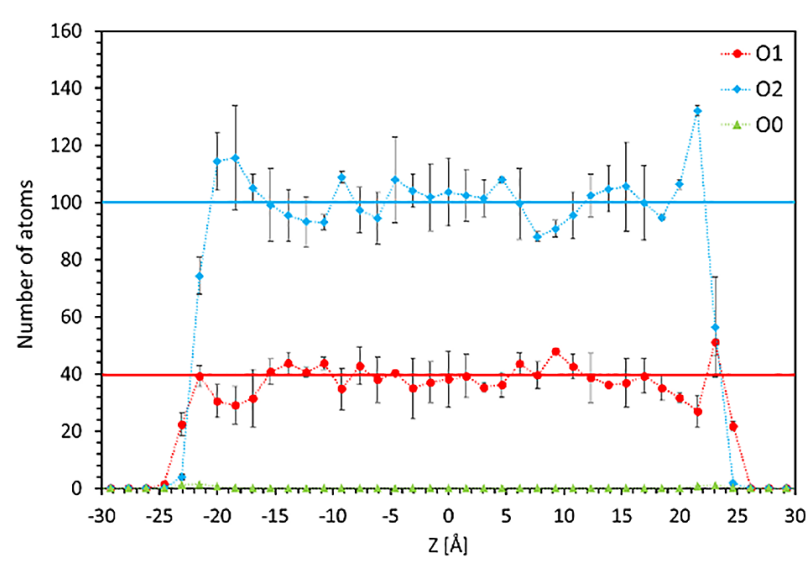

a) broken $\mathrm{Na}_{2} \mathrm{O} \cdot 3 \mathrm{SiO}_{2}-1000 \mathrm{~K}$

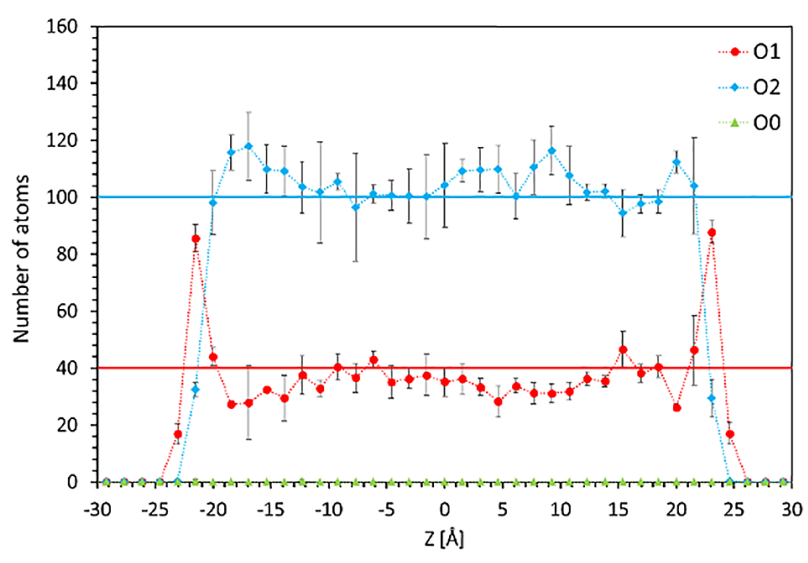

b) moulded $\mathrm{Na}_{2} \mathrm{O} \cdot 3 \mathrm{SiO}_{2}-1000 \mathrm{~K}$

Figure 10. Oxygen coordination number ( $\mathrm{O} 0$ - free oxygen anion, $\mathrm{O} 1$ - non-bridging oxygen, $\mathrm{O} 2$ - bridging oxygen) along the $\mathrm{z}$-axis in the broken and moulded $\mathrm{Na}_{2} \mathrm{O} \cdot 3 \mathrm{SiO}_{2}$ glass relaxed at $1000 \mathrm{~K}$. The error bars are the standard deviations. The thin dotted lines serve as a guide for the eyes.

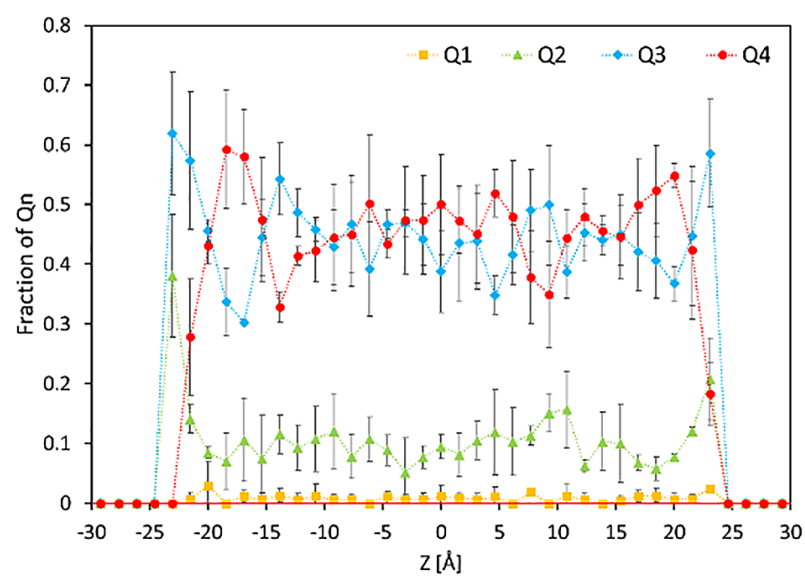

a) broken $\mathrm{Na}_{2} \mathrm{O} \cdot 3 \mathrm{SiO}_{2}-1000 \mathrm{~K}$

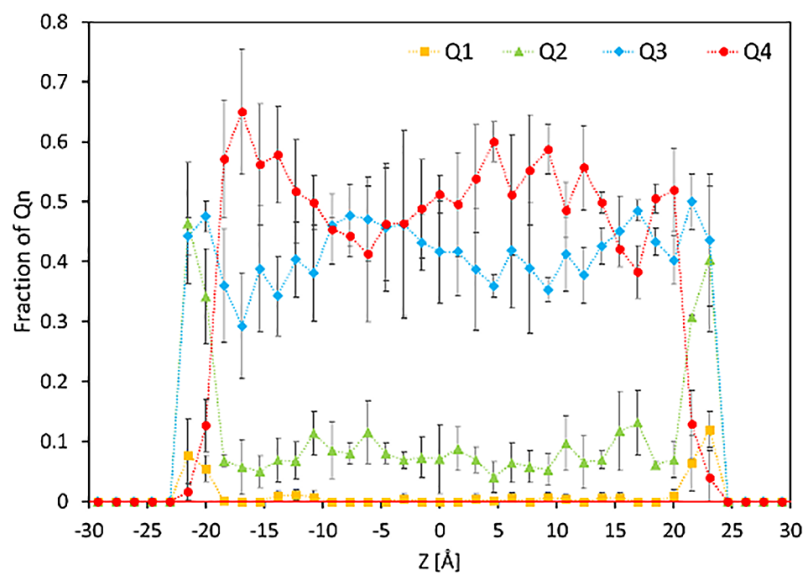

b) moulded $\mathrm{Na}_{2} \mathrm{O} \cdot 3 \mathrm{SiO}_{2}-1000 \mathrm{~K}$

Figure 11. Fractions of the $\mathrm{Q}^{n}$ units along the $z$-axis in the broken and moulded $\mathrm{Na}_{2} \mathrm{O} \cdot 3 \mathrm{SiO}_{2}$ glass relaxed at $1000 \mathrm{~K}$. The error bars are the standard deviations. The thin dotted lines serve as a guide for the eyes.

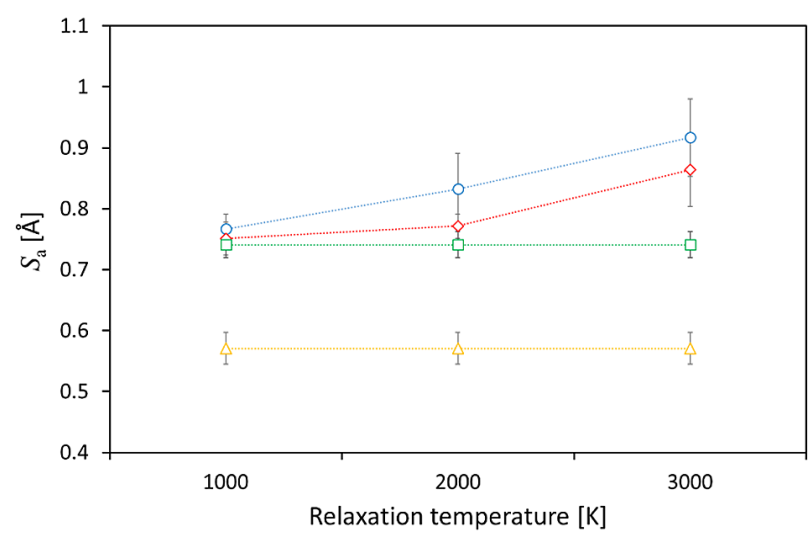

Figure 12. Arithmetic average roughness, $S_{\mathrm{a}}$, of the broken $\mathrm{SiO}_{2}$ glass (blue discs) and the moulded $\mathrm{SiO}_{2}$ glass (red diamonds). For comparison, the unrelaxed moulded glass (green squares) and unrelaxed broken glass (yellow triangles) are also shown. The error bars are the standard deviations. The lines are guides for the eyes.

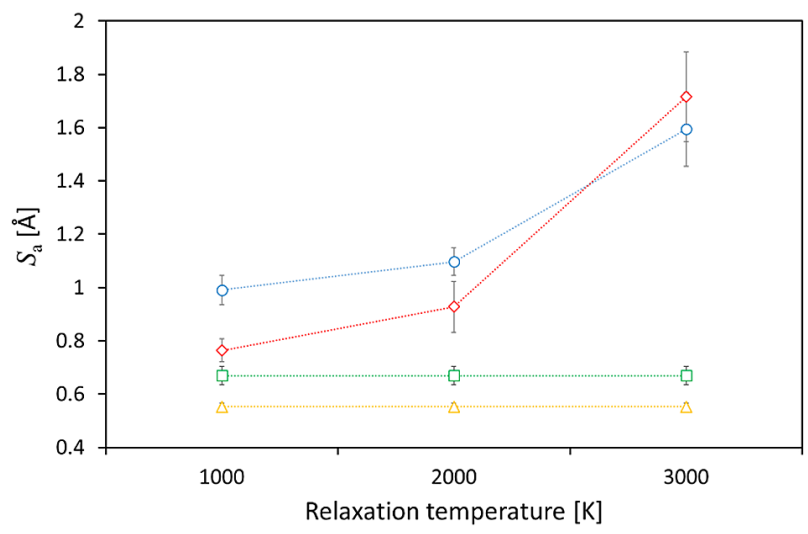

Figure 13. Arithmetic average roughness, $S_{\text {a }}$, of the broken $\mathrm{Na}_{2} \mathrm{O} \cdot 3 \mathrm{SiO}_{2}$ glass (blue discs) and moulded $\mathrm{Na}_{2} \mathrm{O} \cdot 3 \mathrm{SiO}_{2}$ glass (red diamonds). For comparison, the unrelaxed moulded glass (green squares) and unrelaxed broken glass (yellow triangles) are also shown. The error bars are the standard deviations. The lines are guides for the eyes. 
$\mathrm{SiO}_{2}$ glass, shared edges of $\mathrm{SiO}_{4}$ tetrahedra are formed [9]. In a real situation, for example, in the presence of moisture, $\mathrm{OH}$ groups would be attached in these places [12].

On the other hand, the surface formed by moulding has a surface energy that is interestingly in agreement with the experiment, not so much for the $\mathrm{SiO}_{2}$ glass, but for the glass containing a sodium modifier. A similar good agreement was also observed for the other alkaline modifiers, including agreement in the surface activity. For the potassium modifier, a significant reduction in the surface energy was observed for the simulated $\mathrm{K}_{2} \mathrm{O} \cdot 3 \mathrm{SiO}_{2}$ glass compared to the $\mathrm{SiO}_{2}$ glass. The sodium modifier was not surface active and the lithium modifier, on the other hand, significantly increased the surface energy [8]. This is in line with the experimental data available [9].

The surface formation can also be seen in the structural indicators, such as RDF. Basically, it is mainly about the narrowing and widening peaks. However, the formation of the shared edges between the $\mathrm{SiO}_{4}$ tetrahedra can be clearly seen in the RDF $\mathrm{Si}-\mathrm{Si}$. These findings are consistent with previous published articles, most recently with a paper that examined a significantly larger MD system $\mathrm{Na}_{2} \mathrm{O} \cdot \mathrm{SiO}_{2}$ with 23000000 atoms [10].

A much better idea of the surface structure is provided by the density of the atoms or other structural groupings along the z-axis (i.e., perpendicular to the surface plane). In the case of the broken $\mathrm{SiO}_{2}$ glass relaxed at $1000 \mathrm{~K}$, there is a significant increase in the silicon in the relaxed and non-relaxed moulded glass. This can be explained by the $2 \mathrm{D}$ relaxation of the $\mathrm{SiO}_{4}$ tetrahedra that points one of the vertices towards the bulk of the glass. If, for example, $\mathrm{OH}$ groups are not available, this is actually quite an effective way to saturate the broken bonds (dangling oxygen) of the tetrahedra.

The reorientation of the Si tetrahedra is not necessary for the sodium-modified glasses. An increased proportion of sodium on the surface is observed [10]. This is related to the higher proportion of non-bridging oxygen, and lastly, a higher proportion of $\mathrm{Q}^{n}$ units with a lower number of bridging oxygens, namely $\mathrm{Q}^{2}$ a $\mathrm{Q}^{1}$.

The two methods of preparing the glass surface compared here give surfaces that are relatively smooth, for example, in contrast to the paper [10], where glass surfaces were formed freely in a vacuum or broken by tensile stress. The $\mathrm{Na}_{2} \mathrm{O} \cdot 3 \mathrm{SiO}_{2}$ glass was found to be rougher than the glass $\mathrm{SiO}_{2}$, because the surface structure is significantly modified by sodium ions. At higher relaxation temperatures, the roughness increases further.

\section{CONCLUSIONS}

$\mathrm{Na}_{2} \mathrm{O} \cdot 3 \mathrm{SiO}_{2}$ and $\mathrm{SiO}_{2}$ glass surfaces were prepared in two ways using molecular dynamics. In the first rather traditional method, the surface of the glass was formed by dividing the bulk sample by a plane and inserting a sufficiently thick vacuum layer. The system was then relaxed at elevated temperatures (up to $3000 \mathrm{~K}$ ). This situation roughly corresponded to the glass-breaking process. In the second method, the surface was present from the very beginning and was maintained by an external force field that mimics the wall of the mould. The moulded surface was again relaxed at elevated temperatures (up to $3000 \mathrm{~K}$ ). This situation roughly corresponds to the glass-forming process.

The structure of the glass surface prepared by both methods was compared with that of bulk glass using radial distribution functions, distributions of the coordination number of the atom species and $\mathrm{Q}^{n}$ units depending on the z-coordinate.

It is clear from the comparison that the moulding method generates significantly less surface defects, such as shared edges of $\mathrm{SiO}_{4}$ tetrahedra, while giving a relatively smoother surface. This study is the first part of extensive research activities on the theme of functional modifications of glass surfaces.

\section{Acknowledgements}

The work was supported by the Ministry of Education, Youth and Sports of the Czech Republic by the project LTT20001.

\section{REFERENCES}

1. Todorov I.T., Smith W., Trachenko K., Dove M.T. (2006): DL_POLY_3: new dimensions in molecular dynamics simulations via massive parallelism, Journal of Materials Chemistry, 16, 1911-1918. doi: 10.1039/B517931A

2. van Beest B.W.H., Kramer G.J., van Santen R.A. (1990): Force fields for silicas and aluminophosphates based on ab initio calculations. Physical Review Letters, 64, 1955. doi: 10.1103/PhysRevLett.64.1955

3. Roder A., Kob W., Binder K. (2001): Structure and dynamics of amorphous silica surfaces. The Journal of Chemical Physics, 114, 7602-7614. doi: 10.1063/1.1360257

4. Abbas A., Delaye J.-M., Ghaleb D., CALAS G. (2003): Molecular dynamics study of the structure and dynamic behavior at the surface of a silicate glass. Journal of NonCrystalline Solids, 293-315, 187-196. doi: 10.1016/S00223093(02)01432-1

5. Gedeon O. (2015): Molecular dynamics of vitreous silica - Variations in potentials and simulation regimes. Journal of Non-Crystalline Solids, 426, 103-109. doi: 10.1016/j. jnoncrysol.2015.07.006

6. Gedeon O. (2017): Medium range order and configurational entropy of vitreous silica. Physics and Chemistry of GlassesEuropean Journal of Glass Science and Technology Part B, 59, 27-33. doi: 10.13036/17533562.59.1.007

7. Gale J.D.: https://gulp.curtin.edu.au/local/docs/gulp/libs/ bks.lib. Accessed 7 Sep 2021.

8. Macháček J., Gedeon O.: will be published.

9. Shartsis L., Spinner S. (1951): Surface Tension of Molten Alkali Silicates. Journal of Research of the National Bureau of Standards, 46, 385-390. 
10. Zhang Z., Ispas S., Kob W. (2020): The critical role of the interaction potential and simulation protocol for the structural and mechanical properties of sodosilicate glasses. The Journal of Chemical Physics, 153, 124503. doi: 10. 1016/j.jnoncrysol.2020.119895

11. Macháček J., Gedeon O. (2003): Structure of binary alkali silicate glasses - structural modifications caused by various alkali ions. Physics and Chemistry of Glasses, 44, 308-312.

12. Rimola A., Costa D., Sodupe M., Lambert J.-F., Ugliengo P. (2016): Silica Surface Features and Their Role in the Adsorption of Biomolecules: Computational Modeling and Experiments. Chemical Reviews, 113, 4216-4313. doi: $10.1021 / \mathrm{cr} 3003054$

13. Sholl D.S., Steckel. J.A. (2009). Density Functional Theory: A Practical Introduction, John Wiley \& Sons, Inc.

14. Machacek J., Gedeon O., Liska M., Marhoul F. (2010): Molecular simulations of silicate melts doped with sulphur and nitrogen. Journal of Non-Crystalline Solids, 356, 24582464. doi: 10.1016/j.jnoncrysol.2010.02.018

15. Gedeon O., Machacek J., Liska M. (2002): Static energy hypersurface mapping of potassium cations in potassium silicate. Physics and Chemistry of Glasses, 43, 241-246. 